\title{
Pushover Analysis of the Concrete Cassette Structure of Multi-story Long-span Industrial Buildings
}

\author{
Xianhui FENG \\ Space structure research center \\ Guizhou University \\ Guiyang, China \\ E-mail: 690243250@qq.com \\ Qi CAI \\ Space structure research center \\ Guizhou University \\ Guiyang, China
}

\author{
Kejian MA \\ Space structure research center \\ Guizhou University \\ Guiyang, China
}

\begin{abstract}
Pushover analysis, a computing method that combines nonlinear procedure with response spectrum and graph method, is an important technique for performance-based seismic design. In this paper, the fundamental principles and method of pushover analysis are introduced and then SAP2000 is used to execute the pushover analysis and performance evaluation of the concrete cassette structure. This kind of structural system possesses three-dimensional mechanical properties. It offers spacious rooms due to the long span of concrete vierendeel grid slab floor and the absence of beams and columns within. And it is characterized for its easy construction, aesthetic appearance, and vertical space economy.
\end{abstract}

Keywords-pushover analysis; nonlinear static analysis; cassette structure; long-span floor; diag-laid orthogonal grid

\section{INTRODUCTION}

As one of the primary load-carrying building structural members, floor system shoulders vertical load and transfers lateral loads. Generally, floor construction cost accounts for a portion between $20 \%$ and $30 \%$ of the total construction cost of a project, which enlarges with the increase of the number of building floors. Meanwhile, for a reinforced concrete high-rise building, floor self-weight could take up about $50 \%$ to $60 \%$ of its total weight. As for long-span building with a span more than $18 \mathrm{~m}$, this number can even locate in among $60 \%$ and $80 \%$. It is hence crucial to control floor construction cost and floor self-weight from the perspective of overall building. Plus, longspan spatial structure without columns has become common among modern buildings, making it significant to select reasonably an appropriate floor system. In order to remove the restraints of high construction cost and large investment requirement of conventional floor structural systems on the application of single-story long-span public/industrial buildings, Academician Ma Kejian of Chinese Academy of Engineering academicians proposed a new floor system, i.e. precast monolithic cassette structure in a form of diag-laid orthogonal concrete space grid, and put it into practice in the Anshun City Sports Center, Guizhou, P.R.C.

Nonlinear static procedure gains its popularity in seismic performance evaluation of existing and new structures recently.

\section{Ben CHEN}

Shenyang railway bureau line bridge engineering company Shenyang, China

In this paper, based on Chinese codes, elastic design and check of the cassette structure of interest under the action of minor earthquake are conducted via the pushover functionality of the finite element software SAP 2000. The pushover analysis could not only predict the potential failure mechanisms of the structure of interest under major earthquake, but also unveil the possible weak points that would fail in advance, which paves an importance basis for structural seismic design.

\section{FUNDAMENTAL PRINCIPLES OF NONLINEAR STATIC ANALYSIS}

In a pushover analysis, a monotonically increasing lateral load pattern, distributed along structural vertical direction, is imposed on the structure of concern until it turns into an institution or the target displacement of structural top reaches a predetermined target value, so as to position the weak points and other nonlinear responses and to determine whether the deformability of the structure of concern and its members could meet the design and function-ability requirement when subjected to potential ground motion input.

\section{A. Base Shear-top Displacement Curve}

Fig. 1 presents the base shear-top displacement curve of a structure of concern found by imposing a monotonically increasing lateral load on the structure

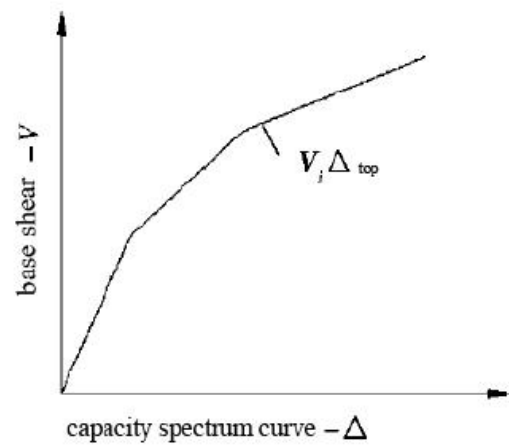

Figure 1. Pushover curve. 


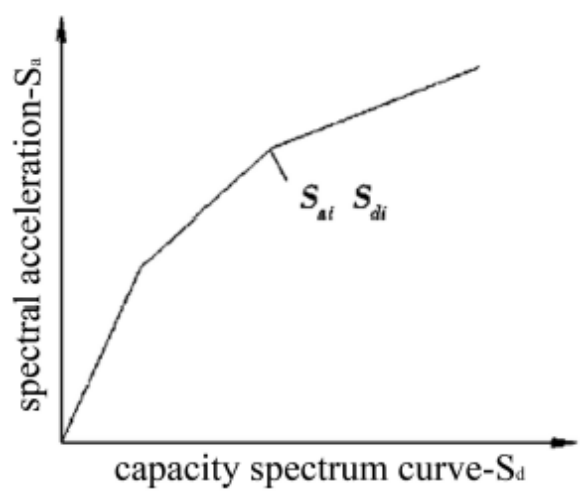

Figure 2. capacity spectrum curve.

\section{B. Capacity Spectrum}

First mode would dominate structural seismic response for a normal building structure. It thus is feasible to substitute the original structure with equivalent single degree of freedom (SDOF) system. Thereby, the base shear vs. top displacement curve could be transformed into the spectral acceleration vs. spectral displacement curve, shown in Fig. 2. Referred are the following equations:

$$
\begin{gathered}
S_{a i}=\frac{V_{i} / G}{\alpha_{1}} \\
S_{d i}=\frac{u_{i}}{\gamma_{1} \varphi_{1, u}} \\
\alpha_{1}=\frac{\sum_{i=1}^{n}\left(m_{i} \varphi_{i 1}\right)}{\sum_{1}^{n}\left(m_{i} \varphi_{i 1}^{2}\right)} \\
\gamma_{1}=\frac{\sum_{i=1}^{n}\left(m_{i} \varphi_{i 1}\right)}{\sum_{i=1}^{n} m_{i} \sum_{1}^{n}\left(m_{i} \varphi_{i 1}^{2}\right)}
\end{gathered}
$$

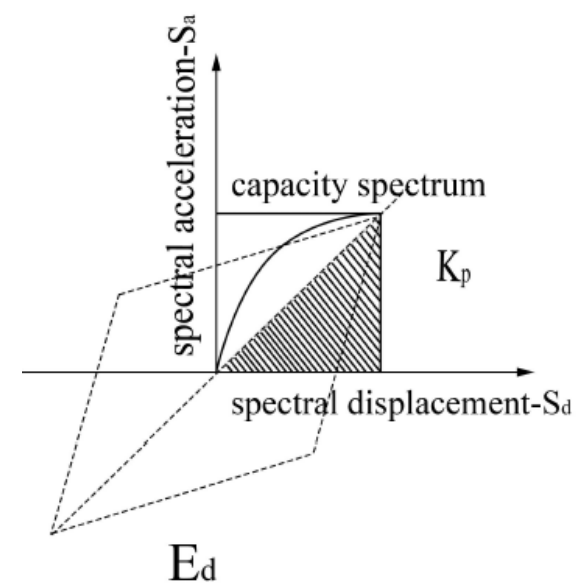

Figure 3. Response spectrum with damping reduced.

Where, $G$ is the total representative value of the equivalent load; $\varphi_{1, u}$ denotes the structural top displacement of first mode; $\alpha_{1}$ represents the modal mass coefficient of first mode; $\gamma_{1}$ is the modal participation coefficient; $\mathrm{m}_{\mathrm{i}}$ denotes the mass of $i$ th floor; and $\varphi_{\mathrm{i} 1}$ represents the amplitude of mass point $i$ of first mode.

\section{Demand Spectrum}

Code-specified acceleration response spectrum should be adopted. In accordance with the equation of motion of elastic SDOF system, it could be found that the following relationship exists between $S_{a}$ and $S_{d}$.

$$
\begin{gathered}
S_{a}=\frac{4 \pi^{2}}{T^{2}} S_{d} \\
\zeta=\frac{E_{d}}{4 \pi E_{s}}
\end{gathered}
$$

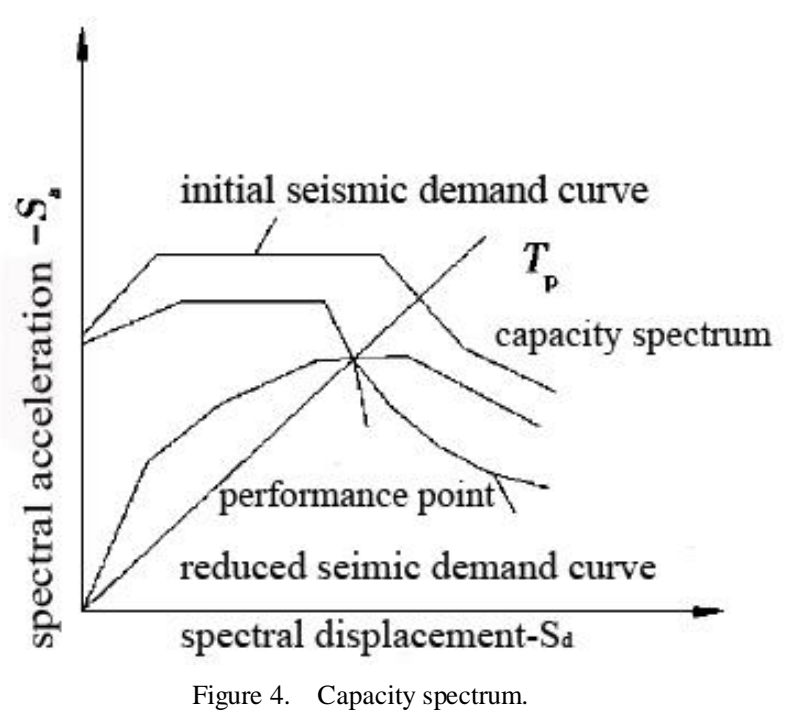

When the structure steps into its nonlinearity under earthquake action, the structural energy-dissipation capacity 
could be represented by a structural viscous damper. The seismic demand spectrum should then be reduced. On the other hand, the hysteretic damping is associated with the area enclosed by the hysteretic cycle. Therefore, equivalent damping is evaluated using bilinear curve to represent capacity spectrum curve when hysteretic curve is to be set.

\section{Demand Spectrum}

The performance point is defined as the intersection of capacity curve and the demand spectrum for some level earthquake when put in the same coordinates. Structural seismic capacity could be indicated by the performance point. If there is no intersection, measures should be taken to counter the deficiency of structural seismic capacity. Otherwise, if there does exist an intersection between the two curves, the displacement corresponding to the intersection is the spectral displacement of the equivalent SDOF system. With the help of Base shear -top roof displacement Curve, The distribution of structural plastic hinges could be determined by transforming spectral displacement back to the top displacement of the original structure. A modification or a reinforcement of the design plan for an in-design building could be generated and then put into practice.

\section{Design Methodology}

\section{A. Design Model-Cassette structure-a Diag-laid Orthogonal Vierendeel Space Grid}

Diag-laid orthogonal vierendeel space grid is the best structural form where bidirectional vierendeel truss would experience a more uniform stress state, when the structural plan aspect ratio (long side-to- short side) is larger than 1.5, shown in Fig. 5. The shorter truss serves as an elastic shore of the longer truss, thus resulting in a more uniform stress state of the bars, illustrated in Fig. 6. Such structures would remain intact after the completion of their construction which was 20 years or so ago, e.g. Anshun City Sports Center, Guizhou, the comprehensive building of Guizhou Province Urban and Rural Construction School, the Guizhou City Torch Farmers' Market. The floor system used here in the model is exactly the diag-laid orthogonal vierendeel space grid.

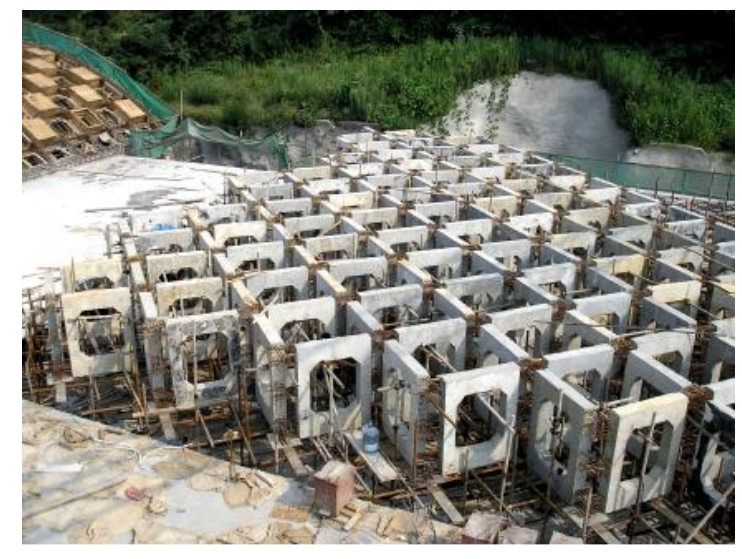

Figure 5. Prefabricated latticed vierendeel space grid.

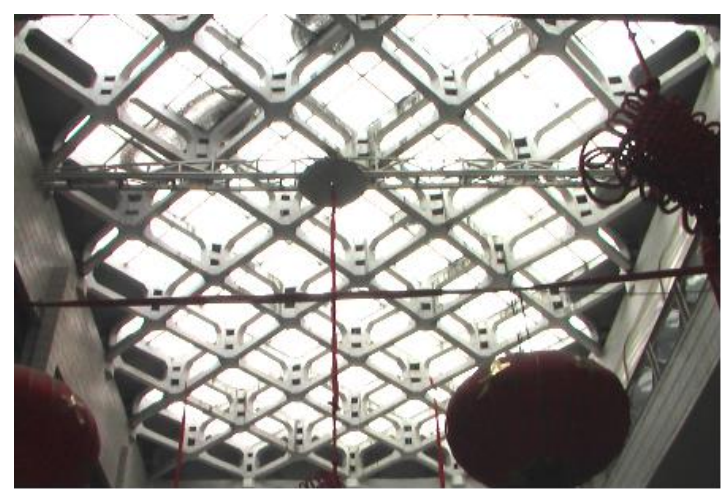

Figure 6. Vierendeel space grids.

\section{B. Project Overview}

The to-be-constructed Guiyang Sports Center is designed according to Chinese codes. There are altogether three stories, whose story heights are $9 \mathrm{~m}, 6.5 \mathrm{~m}$ and $6.5 \mathrm{~m}$,adding up to a total height of $22 \mathrm{~m}$. The building plan is of $24 \mathrm{~m} \times 40 \mathrm{~m}$. Total architectural area is $2880 \mathrm{~m}^{2}$. The column spacing for edge columns is $4 \mathrm{~m}$. The seismic fortification intensity is 6 degree, namely, $0.05 \mathrm{~g}$; the design seismic group is II, and the basic wind pressure is $0.2 \mathrm{kN} / \mathrm{m}^{2}$ for the proposed site. In terms of principle structural design loads, the floor permanent load is $2 \mathrm{kN} / \mathrm{m}^{2}$ as the equivalent linear load of exterior self-weight takes a value of $6.5 \mathrm{KN} / \mathrm{m}$. With the possible flexible space partition taken into consideration, partition walls are computed as equivalent uniformly distributed load, rendering the floor live load a total value of $4 \mathrm{KN} / \mathrm{m}^{2}$. On basis of site engineering geological investigation report, the site class is II, and thus the site characteristic period $\mathrm{Tg}$ is $0.35 \mathrm{~s}$ and the period reduction coefficient is 1. Structural damping ratio is 0.04 while structural accidental eccentricity should be taken consideration for. 15 modes are used for calculation for the structural analysis. The frame structure consists of structural members, including wall column, middle column, inter-story horizontal beam, and frame beam and cast-in-situ phosphogypsum wall. Generally, wall columns locate in the vertices of column grids and the partition wall of each room. Middle columns are installed in among wall columns.

\section{Calculation Model and Principle Design Paramenters}

In the model for simulation, beam element is employed to simulate the rib beams, shear key, and the interstory beams of the vierendeel sandwich slab. Bidirectional moment and shear are considered for interstory beams and shear keys, respectively. V2, V3 hinge are placed in both ends of the shear keys and M2, M3 hinges are placed in both ends of the interstory beams Upper ribs of the vierendeel beams are designed as compression-flexural member. Lower ribs of the vierendeel beams are taken as compression-flexural members where hinge $\mathrm{P}$ and hinge M3 are installed in their ends. The coupling effect of axial force and bending actions is considered for frame columns whose both ends installs P-M2-M3 hinge. The parameters of the plastic hinges take the default value of the program. In this simulation, acceleration loading mode is adopted and as the structure is of single span and multilayer, the target displacement is imposed along the Y-direction, the direction of its single span. The target displacement is set to be 
the $2 \%$ of total building structural height, that is, $440 \mathrm{~mm}$. Fig. 7 exhibits the scheme of the cassette structure, and Fig. 8 shows the three-dimensional calculation model.

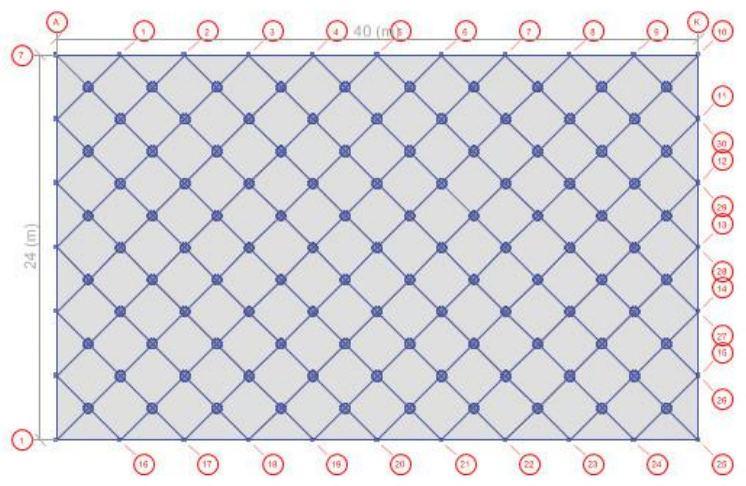

Figure 7. Structural scheme.

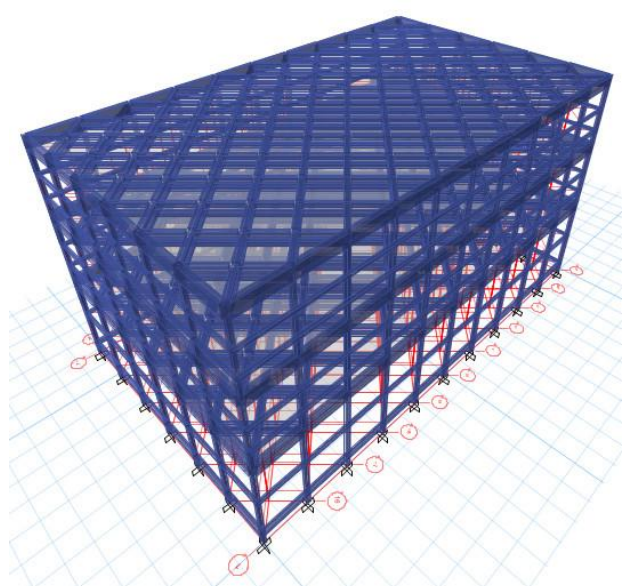

Figure 8. Three-dimensional calculation model.

\section{RESPONSE SPECTRUM ANALYSIS}

Tab.1 presents the dynamic characteristics of the cassette structure. It reads that the lateral stiffness of cassette structure is sufficient and the period ratio 0.69 is far less than the limit prescribed by the Chinese code Technical Specification for Concrete Structures of Tall Building (JGJ3-2010). In other words, the cassette structure meets the code requirement, and its torsional performance is good. The former three modes of the cassette structure could be found in Fig. 9, Fig. 10 and Fig. 11 .

TABLE I. Structural DYNAMIC CHARACTERISTICS

\begin{tabular}{|c|c|c|c|c|}
\hline $\begin{array}{c}\text { Structural } \\
\text { system }\end{array}$ & $\begin{array}{c}\text { Mod } \\
\mathbf{e}\end{array}$ & Period/s & $\begin{array}{c}\text { Dynamic } \\
\text { Characteristics }\end{array}$ & $\begin{array}{c}\text { Torsional- } \\
\text { translational } \\
\text { period raito }\end{array}$ \\
\hline $\begin{array}{c}\text { Cassette } \\
\text { structure }\end{array}$ & 1 & 1.560 & y-translation & \\
& 3 & 1.501 & x-translation & 0.69 \\
torsion & 1.080 & \multicolumn{2}{|c|}{} \\
\hline
\end{tabular}

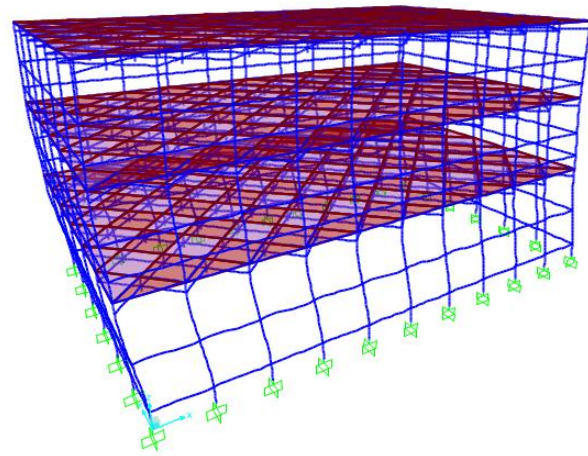

Figure 9. Mode 1.

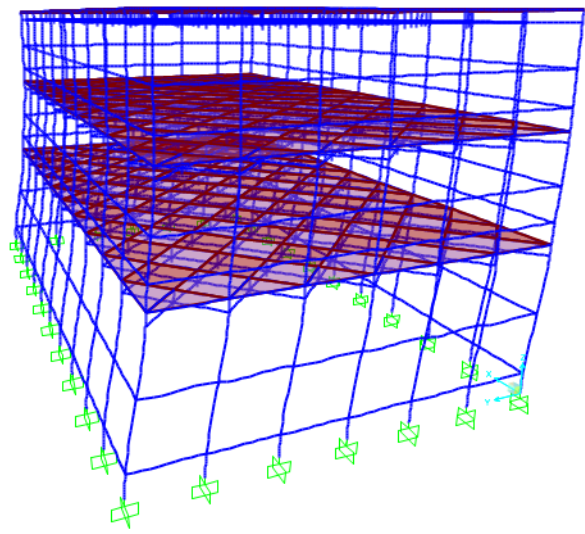

Figure 10. Mode 2.

The maximum structural displacement is obtained adopting modal decomposition response spectrum method, shown in Tab.2. Rigid diaphragm is assumed when calculation. The Tab.2 indicates that, the elastic inter-story drift is within the limit 1/250 stipulated by Code for Seismic Design of Buildings (GB500011-2010), meaning that the cassette structure has an adequate stiffness. When accidental eccentricity is taken into account, structural maximum inter-story drift and the displacement ratio are all smaller than the restraint proposed by Chinese codes, i.e. the structure has a way uniformly distributed stiffness, and a relatively high torsional rigidity.

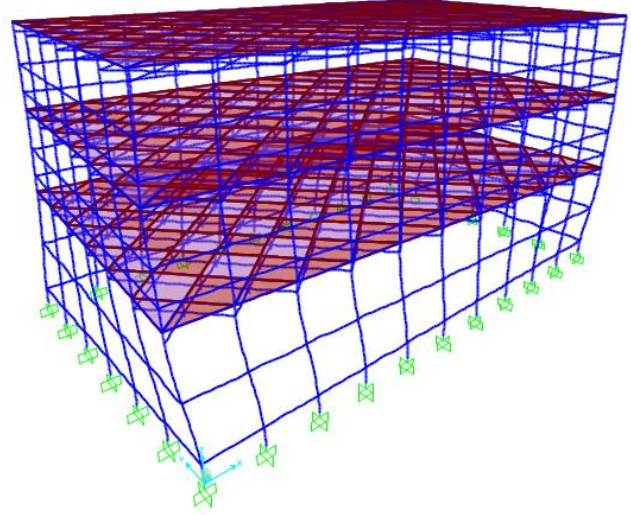

Figure 11. Mode 3. 
TABLE II. StRUCtURAL PERFORMANCE INDEX

\begin{tabular}{|c|c|c|}
\hline \multirow{2}{*}{ Structural Performance Index } & \multicolumn{2}{|c|}{ Cassette Structure } \\
\cline { 2 - 3 } & $\begin{array}{c}\boldsymbol{X} \text { - } \\
\text { direction }\end{array}$ & $\begin{array}{c}\boldsymbol{Y} \text { - } \\
\text { direction }\end{array}$ \\
\hline Maximum inter-story drift & $1 / 1728$ & $1 / 2355$ \\
\hline Displacement ratio & 1.05 & 1.23 \\
\hline
\end{tabular}

\section{CONCLUSION}

This Paper made a research about the multi-story long-span concrete cassette structure, from the standpoint of basis construction, continuum analysis method and practical analysis method, etc. The cassette structure has its grid a height of $950 \mathrm{~mm}$ and the open-web slab can allow the passing through of pipes, improving the efficiency of architectural space. There are neither beams nor columns within interior rooms, which permits free partitioning as occupancies' will. On the other hand, the cassette structure could reduce construction cost. Concrete cassette structure possesses an excellent structural mechanical performance, economical construction cost, as well as good social and economic benefit. It is thus profoundly meaningful to further study and innovate this type of structural system. This paper is just a preliminary study of cassette structural system. Further studies are necessary to perfect our understanding of cassette structures, and to pave a broad theoretical foundation and offer a robust technical support for its application.

\section{ACKNOWLEDGMENT}

Supported by the 12th "five-year" National Science and Technology Support Plan of China (2011BAJ09B01-01); Guizhou Province Science and Technology Innovation Talents Team Building ([2014]4012); Graduate Student Innovation Fund of Guizhou University (2016001)

\section{REFERENCES}

[1] HE Peng-hui, WEN Huan-ling, GAO Xiao-li. Push-Over Analysis Based On the Basic Principle And Design Method, Low Temperature Architecture Technology[J],2009

[2] SONG Ling-ling, ZHANG Hua-gang et al. Application of Box-Structure with Space Steel Grid in Multi-story Industrial Plant [J], Journal of Guizhou University (Natural Science Edition), 2015

[3] Song Shuai, Ma Fenghai et al. Design and application of orthogonal and diagnal cassette structure of assembled overall spatial steel grid in the multi-storey large-span industrial buildings [J], Building Structure, 2014

[4] Ma Ke-Jian, Shen Bo, Hu Lan. New Super Long-Span Pre-stress Space Steel Grid Structure, China Communications Press, 2011, ISBN:9787114094873

[5] Ma Kejian, Wei Minghui et al. Design and research of prefabricated monolithic and pre-stress vierendeel space grid[C], 4th space structure academic conference, 1988. 